\title{
Masked priming of words and nonwords in a naming task: Further evidence for a nonlexical basis for priming
}

\author{
MICHAEL E. J. MASSON \\ University of Victoria, Victoria, British Columbia, Canada \\ and \\ MATTHEW I. ISAAK \\ Rice University, Houston, Texas
}

\begin{abstract}
Masked priming effects in word identification tasks such as lexical decision and word naming have been attributed to a lexical mechanism whereby the masked prime opens a lexical entry corresponding to the target word. Two experiments are reported in which masked repetition priming effects of similar magnitude were obtained with word and nonword targets in a naming task. Masked orthographic priming was more stable for word than for nonword targets, although morphological primes produced no advantage beyond that achieved by matched orthographic primes. These results, taken together with the recent finding that repetition priming of nonwords can be obtained in the lexical decision task, support the view that masked priming of words and nonwords has a nonlexical component. We suggest that masked primes can enhance target identification by contributing to the construction of an orthographic or a phonological representation of the target, regardless of the target's lexical status.
\end{abstract}

A potentially informative means of examining the early stages of word identification involves the brief presentation of a masked prime prior to the onset of a target word (see, e.g., Evett \& Humphreys, 1981; Forster \& Davis, 1984; Humphreys, Besner, \& Quinlan, 1988; Humphreys, Evett, \& Quinlan, 1990). The rationale behind this technique is that processing of the briefly presented prime provides a snapshot of the first few moments of word identification. The influence of that processing is revealed in the process of identifying a subsequently presented target. In particular, when the prime and target are orthographically identical, although different in letter case (e.g., salt-SALT), target identification occurs more rapidly than when the prime and target are unrelated (e.g., bond-SALT). This facilitation is referred to as the masked repetition priming effect.

Three important constraints on the masked repetition priming effect have been found, leading to the conclusion that the effect is caused by the prime opening a lexical entry that corresponds to the target word (Forster \& Davis, 1984). These constraints also serve to distinguish masked repetition priming from long-term repetition priming, in

The research reported here was supported by a research grant from the Natural Sciences and Engineering Research Council of Canada to M.E.J.M. M.I.I. is now at the Rochester Institute of Technology. We thank Kenneth Forster, Glyn Humphreys, and Robert Lorch for helpful comments on an earlier version of this article. Correspondence should be addressed to M. E. J. Masson, Department of Psychology, University of Victoria, P.O. Box 3050, Victoria, BC V8W 3P5, Canada (e-mail: mmasson@uvic.ca). which primes are clearly visible and typically require a response on the part of the subject. First, masked priming dissipates substantially within about $500 \mathrm{msec}$ of the prime event and is undetectable by $9 \mathrm{sec}$ after the prime presentation (Forster \& Davis, 1984), whereas long-term priming on word identification tasks can be found minutes or even hours after the priming episode (Forster \& Davis, 1984; Jacoby \& Dallas, 1981; Scarborough, Cortese, \& Scarborough, 1977). Second, long-term repetition priming has been observed for both word and nonword targets in the lexical decision task (Besner \& Swan, 1982; Kirsner \& Smith, 1974; McKone, 1995; Norris, 1984; Scarborough et al., 1977). In contrast, although masked repetition priming of word targets has consistently been found with the lexical decision task, nonword targets have typically failed to yield such an effect (Forster, 1987; Forster \& Davis, 1984; Forster, Davis, Schoknecht, \& Carter, 1987; Rajaram \& Neely, 1992, for nonstudied nonwords), although exceptions to this pattern have been reported (see below). Third, long-term repetition priming effects generally are larger for low-frequency words than for high-frequency words (Duchek \& Neely, 1989; Forster \& Davis, 1984; Norris, 1984; Rajaram \& Neely, 1992; Scarborough et al., 1977), whereas masked repetition priming effects are equally strong for high- and low-frequency words (Ferrand, Grainger, \& Segui, 1994; Forster \& Davis, 1984; Forster et al., 1987; Humphreys et al., 1988; Humphreys, Evett, Quinlan, \& Besner, 1987; Rajaram \& Neely, 1992; Segui \& Grainger, 1990; Sereno, 1991).

The differences between masked and long-term repetition priming effects suggest the possibility that the two 
effects are mediated by different mechanisms. Forster and Davis (1984) accepted the possibility that long-term repetition priming might result from the influence of episodic memory for the earlier presentation of a target (see also Jacoby \& Dallas, 1981). They proposed, however, that masked presentation of a prime minimizes the possibility that an episodic representation of the prime event would be constructed. Masked repetition priming, then, would result from the effects of a temporary, ongoing process. Specifically, Forster and Davis (1984) proposed that the masked prime opened its corresponding lexical entry so that when its matching target was presented, a quicker lexical decision could be made because the relevant lexical entry would already be open.

This explanation accounts for the three constraints on masked repetition priming just described. A word's lexical entry would not be kept open indefinitely, particularly if other words are subsequently presented. Presentation of intervening words between a masked prime and target, or perhaps simply the passage of time, would be assumed to lead to closure of the entry opened by the prime. Word frequency is not expected to influence the size of masked repetition priming effects according to lexical search theories of word identification (C. A. Becker, 1979; Forster, 1976; Stanners \& Forbach, 1973). These theories propose that lexical entries for high-frequency words are searched earlier than entries for lowfrequency words, thereby producing an effect of word frequency on identification time. The effect of masked repetition priming is to increase the speed with which an entry is accessed once it has been located in the search, but the search process itself should be unaffected by priming. Thus, high- and low-frequency words should benefit equally from masked repetition priming. In addition, because the basis of masked repetition priming is early opening of an existing lexical entry, it is logically impossible for nonword targets to benefit from this form of priming.

Although masked repetition priming effects in the lexical decision task are not long-lasting and have been found consistently to be similar for high- and low-frequency words, the absence of masked repetition priming of nonword targets is less clearly established. Nonword targets in this task have shown a reliable effect of priming. Forster (1985) and Sereno (1991) obtained masked repetition effects in the lexical decision task for nonword targets, although these effects were smaller in magnitude than effects found with word targets. More recently, Bodner and Masson (1997) argued that priming of nonword targets in the lexical decision task might be difficult to detect because the processing fluency induced by a masked repetition prime could be taken by subjects as evidence in favor of a WORD response. Making a correct response to primed nonword targets would require extra time to overcome the tendency to misclassify such targets (Feustel, Shiffrin, \& Salasoo, 1983; Kirsner \& Speelman, 1996).
Following the lead of Whittlesea and Jacoby (1990), Bodner and Masson (1997) reasoned that if processing of target items were made more difficult, subjects might rely more on the processing resources provided by the prime, thereby enhancing the priming effect. At the same time, making the targets more difficult to identify should lead subjects to rely less on a sense of processing fluency to make a lexical decision and more on analytic processing of the target. Taken together, these factors should enable rather large priming effects to be found with nonword targets. Bodner and Masson found that by making lexical decisions more difficult, either through degrading targets with case alternation or by using pseudohomophones as nonwords, masked repetition priming effects of similar magnitude were found for word and nonword targets. In addition, they replicated the finding that word frequency and priming were additive.

The demonstration that nonword targets can yield as much masked repetition priming as word targets casts doubt on the proposal that this kind of priming arises because the prime opens the target's lexical entry. An alternative possibility advanced by Bodner and Masson (1997) is that a masked prime is processed to the point of constructing an orthographic representation. That representation may continue to be available or active at the time the target is presented and, by virtue of the identity relation between the prime and target, be used in the construction of the target's orthographic representation. A related possibility considered by Bodner and Masson is that an episodic representation of the prime's orthography may be created and subsequently recruited during processing of the target. Bodner and Masson also suggested that if the priming effect is based on processes involved in constructing an orthographic representation of the target, word frequency might not affect priming because frequency information may be restricted to higher levels of processing (see, e.g., Besner \& Smith, 1992; Borowsky \& Besner, 1993).

Yet another possibility is that the benefit of the prime event derives not from its orthographic representation, but from the construction of a phonological code. Results from studies using masked phonological primes have shown that a phonological representation of a masked prime can be constructed quickly enough to influence processing of a subsequent target (e.g., Grainger \& Ferrand, 1991; Lukatela \& Turvey, 1994a, 1994b; Perfetti \& Bell, 1991). Regardless of whether the functional representation is orthographic or phonological, our proposal is that it need not involve the opening of a lexical entry. Rather, presentation of a masked prime may serve to engage orthographic or phonological processing that maps closely to the corresponding processes that are engaged when the target is subsequently presented. That processing overlap is presumed to be the basis for masked priming effects. Both nonword and word targets stand to benefit from the groundwork laid by processing of an identical 
prime. On this view, the two types of target should show similar amounts of masked repetition priming, as found by Bodner and Masson (1997).

As noted, however, assessing priming effects for nonword targets using the lexical decision task is complicated by the possible tradeoff between the benefits of processing fluency created by a prime and the requirement to classify the target as a nonword. Bodner and Masson (1997) found it necessary to increase the difficulty of making lexical decisions to obtain substantial priming with nonword targets.

An alternative strategy for demonstrating masked repetition priming of nonword targets is to avoid the tension between processing fluency and making a negative response to nonwords that is inherent in the lexical decision task. The speeded naming task is an attractive alternative to the lexical decision task because it has been used extensively in various word identification paradigms. The naming task does not involve a binary decision; making a correct response to nonwords does not require subjects to discount processing benefits that might accrue to those targets through masked priming. Whatever processing benefit might be derived from masked primes should increase the efficiency of pronouncing the target.

Moreover, Forster and Davis (1991) have examined masked repetition priming with the naming task. They discovered a Stroop-like interference effect when the masked prime and target differ in their first phoneme, marked by a tendency on the part of subjects to pronounce the first phoneme of the prime or to blend that phoneme with the target when making a vocal response to the target. To avoid this interference effect, Forster and Davis (1991) used unrelated primes that shared the same onset as the target. With this precaution in place, they found reliable masked repetition priming of word targets in the naming task. They did not, however, test nonword targets.

Another important result obtained by Forster and Davis (1991) involved primes that were orthographically similar but not identical to target words (e.g., zuro-ZERO). Earlier studies using the lexical decision task had shown that masked primes that were orthographically similar to target words facilitated lexical decisions, but only if the primes and targets had few orthographic neighbors (Forster, 1987; Forster et al., 1987; see also Forster \& Taft, 1994). Forster and Davis (1991) found that masked orthographic priming of words in the naming task also followed this constraint. Thus, it appears that masked priming has a similar basis in lexical decision and in naming.

In the experiments reported here, we adopted the strategy of examining masked priming of word and nonword targets in the naming task. The primary question was whether nonword targets would produce robust masked repetition priming, given that the potential conflict between prime-induced processing fluency and the requirement to classify the target as a nonword would not be operating. Obtaining substantial masked priming of nonword targets under these circumstances would indicate that masked priming effects are not necessarily lexical in nature.
A secondary question addressed by these experiments was whether nonword targets would also produce orthographic priming in the naming task. Naming of word targets is facilitated by masked orthographic primes, provided that the items have few orthographic neighbors (Forster \& Davis, 1991). Our goal in examining orthographic priming in the present experiments, however, was not to explore this constraint. Therefore, the materials used in the experiments reported here were not selected in a manner that systematically varied orthographic neighborhood. Rather, the examination of orthographic priming in these experiments was intended as a preliminary test of the possibility that nonword targets can benefit from orthographically related masked primes.

\section{EXPERIMENT 1}

In Experiment 1, high- and low-frequency words and pronounceable nonwords served as targets in a naming task. Targets were preceded by a masked prime that was identical to the target except for letter case (repetition prime), orthographically similar to the target (orthographic prime), or unrelated to the target except that it shared the first phoneme with the target (unrelated prime). Forster and Davis $(1984,1991)$ obtained similar masked repetition priming effects for high- and low-frequency target words in lexical decision and naming tasks, and we expected to replicate that result. In addition, however, we expected that because the naming task is free of the decisionmaking component that according to Bodner and Masson (1997) serves to interfere with priming of nonword targets in lexical decision, reliable masked repetition priming of nonword targets should be found in the naming task. This expectation follows from the proposal that one possible influence of masked repetition primes is to enable more efficient construction of an orthographic or phonological representation of the target, whether it be a word or a nonword. Similarly, if nonlexical orthographic or phonological processes make a central contribution to masked orthographic priming, we expected that orthographic priming effects should emerge for nonword targets.

\section{Method}

Subjects. The subjects were 36 undergraduate students at the University of Victoria who volunteered to participate. All subjects claimed English as their native language.

Materials. A set of 120 high- and 120 low-frequency words, most of which were taken from the materials used by McRae, Jared, and Seidenberg (1990), served as the target words. Words taken from that source consisted of high- and low-frequency word pairs that were homophones or rhymes (e.g., heard, herd). The targets ranged from three to eight letters in length. High-frequency words occurred more than 25 times per million and low-frequency words occurred fewer than 25 times per million in the Kučera and Francis (1967) norms. The word targets were divided into two lists containing 60 targets of each frequency. Assignment of targets to lists was arbitrary with the constraint that members of phonologically matched high- and low-frequency pairs were assigned to different lists (e.g., if heard was assigned to one list, herd was assigned to the other list) 
An orthographic prime was created for each target by changing one medial letter of the target to form a pronounceabie nonword (e.g., munt-MUST). An unrelated prime was also created for each target by creating a pronounceable nonword of equal length that shared only the same first letter as the target (e.g., mern-MUST). Using the same initial letter controls for the onset effect identified by Forster and Davis (1991), whereby different onsets of primes and targets may produce an interference effect in target pronunciation.

Sixty pronounceable, one-syllable nonword targets, ranging from four to six letters in length, were created by changing one letter in each of 60 different medium-frequency words. Each target was assigned two pronounceable nonword primes that were of the same length as the target. The unrelated prime shared only its first letter with the target (e.g., nalk-NUMP); the orthographic prime was derived from the target nonword in the same manner as orthographic primes for word targets (e.g., nurp-NUMP).

Through an oversight, the orthographic or unrelated prime for a few of the target words was a word rather than a nonword (e.g., heir-HAIR, hewer-HOUND), and in the case of some targets, although the initial letter was the same for the target and its primes, the target's initial phoneme differed from that of its unrelated prime (e.g., crift-CHECK). Data involving targets whose onsets were not identi$\mathrm{cal}$ to the onset of their unrelated prime ( 24 word targets across the two lists and 4 nonword targets) were not included in the analyses reported here. The resulting 216 critical word targets and 56 critical nonword targets and their respective primes are shown in Appendix A. An additional four words and two pronounceable nonwords were chosen for use as practice items.

Design. Each subject was presented one of the two lists of 120 word targets and the list of 60 nonword targets in a naming task. Each of the word target lists was assigned to half the subjects. One third of the targets in the word and nonword lists were assigned to each of three priming conditions: repetition, orthographic, and unrelated. Assignment of word targets to these conditions was done in a manner that ensured that 20 high-and 20 low-frequency targets were assigned to each prime condition. The assignments of word and nonword targets to priming conditions were counterbalanced across subjects so that each item appeared equally often in each priming condition.

Procedure. Instructions and materials were presented to subjects on a video monitor controlled by an Apple II+ microcomputer. The computer was altered to allow synchronization of stimulus presentation with the raster scan cycle of the monitor, which provided stimulus display durations in increments of $16.7 \mathrm{msec}$. In addition, a voice-operated relay was connected to the computer to allow measurement of vocal response latencies. A microphone connected to the voice relay was used to detect vocal responses. Subjects were instructed that each trial would begin with a warning signal followed by a letter string printed in uppercase, and that their task was to read aloud the letter string. They were told that in some cases the letter string would be a word and in other cases it would not. No mention was made of displays occurring between the warning signal and the letter string.
Each trial began with a display of a row of uppercase Xs equal in length to the upcoming target item. This warning signal was in view for $500 \mathrm{msec}$ and then was immediately replaced by a 50 -msec display of the prime stimulus in lowercase letters. The target item printed in uppercase letters then replaced the prime and remained in view until the subject made a vocal response. As soon as a response was detected, the screen was erased, and the experimenter, who watched a separate monitor that displayed the target on each trial, pressed the appropriate key on a keyboard out of the subject's view to create a record of the correctness of the subject's response. The next trial began after a 500-msec pause. Subjects were first given the six practice trials in a random order, each including an identical prime, and then they received the 180 critical trials in a random order. After each block of 60 critical trials, a message appeared on the screen providing the subject an opportunity to take a short break.

\section{Results and Discussion}

Trials on which response latencies were shorter than $200 \mathrm{msec}$ or longer than $1,800 \mathrm{msec}$ were considered outliers and were excluded from the analyses. This criterion eliminated 21 of the 5,904 trials $(0.4 \%)$, which is lower than the maximum exclusion rate of $0.5 \%$ recommended by Ulrich and Miller (1994) to avoid bias when estimating parameters of response latency distributions. Each subject's median latency for correct naming responses and percentage of errors in each condition were computed separately for high- and low-frequency word and nonword targets. Any erroneous pronunciation of the target item or accidental triggering of the voice-operated relay was considered an error. The mean of the median latencies and the error percentages are shown in Table 1. Separate analyses of variance (ANOVAs) were conducted to test the primary hypotheses addressed by Experiment 1 . In each analysis, the Type I error rate was set at .05 . Two versions of each analysis were conducted, one using subjects as the random factor $\left(F_{1}\right)$, and the other using items as the random factor $\left(F_{2}\right)$.

Repetition priming. The most important issue in Experiment 1 was whether nonwords as well as words would yield masked repetition priming in the naming task. The priming effects shown in Table 1 indicate that repetition priming was found among both word and nonword targets. To provide statistical support for this observation, we first analyzed the data from high- and low-frequency words to establish that a repetition priming effect for words had been obtained and to determine whether priming and word frequency were additive. Subjects and items

Table 1

Mean Response Latency (in Milliseconds), Error Percentage, Standard Deviations, and Priming Effect (PE) on Response Latency in Experiment 1

\begin{tabular}{|c|c|c|c|c|c|c|c|c|c|c|c|c|c|c|c|}
\hline \multirow[b]{4}{*}{ Prime } & \multicolumn{15}{|c|}{ Target } \\
\hline & \multicolumn{5}{|c|}{ High Frequency } & \multicolumn{5}{|c|}{ Low Frequency } & \multicolumn{5}{|c|}{ Nonword } \\
\hline & \multicolumn{2}{|c|}{ Latency } & \multicolumn{2}{|c|}{$\%$ Error } & \multirow[b]{2}{*}{$P E$} & \multicolumn{2}{|c|}{ Latency } & \multicolumn{2}{|c|}{$\%$ Error } & \multirow[b]{2}{*}{$\mathrm{PE}$} & \multicolumn{2}{|c|}{ Latency } & \multicolumn{2}{|c|}{$\%$ Error } & \multirow[b]{2}{*}{ PE } \\
\hline & $M$ & $S D$ & $M$ & $S D$ & & $M$ & $S D$ & $M$ & $S D$ & & $M$ & $S D$ & $M$ & $S D$ & \\
\hline Repetition & 530 & 66 & 0.8 & 2.3 & 21 & 550 & 70 & 1.3 & 2.5 & 26 & 596 & 84 & 6.1 & 7.3 & 17 \\
\hline Orthographic & 544 & 73 & 1.1 & 2.2 & 7 & 562 & 75 & 2.2 & 3.4 & 14 & 597 & 89 & 7.9 & 6.5 & 16 \\
\hline Unrelated & 551 & 68 & 0.8 & 1.9 & & 576 & 74 & 3.1 & 4.9 & & 613 & 85 & 6.6 & 7.3 & \\
\hline
\end{tabular}


ANOVAs with word frequency (high vs. low) and prime (repetition vs. unrelated) as factors and response latency as the dependent variable indicated that latencies were shorter for high- than for low-frequency words $\left[F_{1}(1,35)=\right.$ $\left.37.24, M S_{\mathrm{e}}=484, F_{2}(1,214)=13.31, M S_{\mathrm{e}}=4,289\right]$ and that there was a repetition priming effect $\left[F_{1}(1,35)=\right.$ $\left.56.27, M S_{\mathrm{e}}=352, F_{2}(1,214)=19.47, M S_{\mathrm{e}}=2,024\right]$. The priming effect did not interact with word frequency $\left(F_{\mathrm{S}}<1\right)$.

A corresponding analysis of error percentages revealed significant effects of word frequency $\left[F_{1}(1,35)=\right.$ $\left.8.29, M S_{\mathrm{e}}=8.85, F_{2}(1,214)=6.66, M S_{\mathrm{e}}=33.29\right]$, an effect of priming that only approached significance in the subjects analysis $\left[F_{1}(1,35)=3.07, M S_{\mathrm{e}}=7.58, p<\right.$ $\left..09, F_{2}(1,214)=4.00, M S_{\mathrm{e}}=24.41\right]$, and an interaction that only approached significance in the items analysis $\left[F_{1}(1,35)=5.61, M S_{\mathrm{e}}=5.36, F_{2}(1,214)=3.75, M S_{\mathrm{e}}=\right.$ $24.41, p<.06]$. The interaction appears to have resulted from a floor effect among high-frequency words such that errors were too rare for a priming effect to be found. The priming effect found among low-frequency words is consistent with the priming effect found in the latency data and indicates that the latter result was not due to a speed-accuracy tradeoff.

These results replicate findings with the lexical decision task in which word frequency and masked repetition priming are additive (Bodner \& Masson, 1997; Forster \& Davis, 1984). Forster and Davis (1991) found somewhat more priming with low- than with high-frequency words using the naming task, although they did not report a statistical test of that interaction. With the items used here, which were closely matched across the two frequency conditions with respect to phonological patterns, masked repetition priming was not altered by differences in word frequency. We note, however, that the power of this experiment to detect an interaction in which the size of the priming effect for high-frequency words would be only half that observed for low-frequency words (a ratio typical in long-term priming experiments; Forster \& Davis, 1984) was estimated to be .53 for the subjects analysis and 23 for the items analysis. Bodner and Masson (1997) also found rather low power estimates in their attempts to detect this interaction in the lexical decision task, although by combining across experiments they were able to achieve reasonable levels of power and still did not find a reliable interaction.

Masked repetition priming among nonword targets was assessed in ANOVAs with prime (repetition vs. unrelated) as the only factor and response latency and error percentage as the dependent measures. These analyses revealed a significant priming effect on latency $\left[F_{1}(1,35)=\right.$ $\left.10.04, M S_{\mathrm{e}}=515, F_{2}(1,55)=6.28, M S_{\mathrm{e}}=1,330\right]$, but no priming effect on error percentage $(F \mathrm{~s}<1)$.

Having established that nonword targets showed a masked repetition priming effect in naming latency, we compared the size of that effect with the repetition priming effect found among word targets. The repetition priming effect (unrelated prime minus repetition prime) for high- and low-frequency word targets was averaged for each subject to produce a single priming score for word targets in the subjects analysis. Repetition priming scores for word and for nonword target naming latency were then compared in a subjects ANOVA and an items ANOVA. These analyses failed to yield a reliable difference in the size of the priming effect for the two types of target $(F \mathbf{s}<1.1)$. An upper bound on the power of these analyses to detect a difference in priming scores for words and nonwords was computed by assuming a difference equivalent to the magnitude of priming found with word targets (i.e., full priming for word targets but no priming for nonword targets). This upper bound was estimated to be .95 and .58 for the subjects and items analyses, respectively. The relatively low power of the items analysis to detect the maximum possible difference in priming for words and nonwords leaves open the possibility that the true magnitude of priming is larger for words than for nonwords.

The finding that nonword targets show a reliable masked repetition priming effect, although somewhat smaller than that found with word targets, is inconsistent with the view that the only effect of a masked prime is to open a lexical entry for the target (e.g., Forster \& Davis, 1984). Nonword targets have no lexical entries to be opened. Unlike the lexical decision task, the naming task does not involve a binary decision in which word and nonword targets are classified into different categories. Bodner and Masson (1997) showed that the binary decision required by lexical decisions can obscure processing benefits that accrue to nonword targets through masked repetition priming. By removing that task requirement, the word naming task clears the way for a masked repetition priming effect to be revealed among nonword targets.

Orthographic priming. A secondary question addressed in Experiment 1 was whether nonword targets would show a masked orthographic priming effect. The priming effects shown in Table 1 indicate that such an effect was found and that it was similar in magnitude to that found among word targets. These priming effects were tested statistically using a series of ANOVAs similar to those applied to the repetition priming data. First, orthographic priming among word targets was assessed in an ANOVA with word frequency (high vs. low) and prime (orthographic vs. unrelated) as factors. This ANOVA revealed the usual effect of word frequency $\left[F_{1}(1,35)=\right.$ $\left.21.99, M S_{\mathrm{e}}=726, F_{2}(1,214)=13.10, M S_{\mathrm{e}}=3,832\right]$, as well as a significant priming effect $\left[F_{1}(1,35)=8.02\right.$, $\left.M S_{\mathrm{e}}=469, F_{2}(1,214)=8.09, M S_{\mathrm{e}}=2,291\right]$, but no interaction $(F \mathrm{~s}<1.1)$. As in repetition priming, then, the orthographic priming effect was additive with word frequency. The only significant effect in the corresponding analysis of error percentage was that there were fewer errors for high-frequency words $\left[F_{1}(1,35)=11.22, M S_{\mathrm{e}}=\right.$ 9.84, $\left.F_{2}(1,214)=8.31, M S_{\mathrm{e}}=38.33\right]$.

An ANOVA computed with the data from nonword targets also revealed an orthographic priming effect for response latency, but only in the subjects analysis $\left[F_{1}(1,35)=\right.$ 
$\left.9.25, M S_{\mathrm{e}}=479, F_{2}(1,55)=1.64, M S_{\mathrm{e}}=2,064\right]$. There was no priming effect on error percentage for nonword targets $\left(F_{\mathrm{S}}<1.4\right)$. Although orthographic priming among nonwords was reliable only in the subjects analysis, the size of the priming effect averaged across subjects was similar to that found for word targets (Table 1). The lack of a reliable orthographic priming effect in the items analysis indicates that the effect was not consistent across items. A possible reason for this inconsistency is that, like word targets (Forster \& Davis, 1991), orthographic priming of nonword targets may depend on neighborhood density. If the nonword items contain a mixture of highand low-density items, a consistent orthographic priming might not be found in the items analysis.

Conclusion. The results of Experiment 1 confirmed the prediction that masked repetition priming should be found for nonword targets in the naming task. This priming effect suggests the existence of a basis for masked priming that does not involve the priming or opening of well-established lexical representations. Rather, a basis common to words and nonwords, such as the construction of an orthographic or phonological representation from sublexical elements, is indicated.

\section{EXPERIMENT 2}

In Experiment 2, we sought to replicate the masked repetition priming effect with nonwords using a different set of materials. In addition, we examined another source of evidence that has been offered in support of the view that masked priming has a lexical basis. In particular, masked primes that are morphologically related to target words (e.g., made-MAKE) have been shown to generate reliable priming effects in the lexical decision task (Forster et al., 1987; Grainger, Colé, \& Segui, 1991). One might attribute this priming effect to a lexical representation system in which morphologically related entries prime one another. In the Forster et al. study, however, there was no orthographic prime condition involving primes that were not morphologically related to the targets but that were matched to morphological primes with respect to orthographic similarity to targets. Without such a condition, it is not clear whether morphological primes are effective because of their morphological relation to the targets or because of their orthographic similarity.

Although Grainger et al. (1991) controlled for orthographic similarity when demonstrating a morphological priming effect, they also used the lexical decision task. In that task, it is possible that the benefit associated with morphological primes was derived from the decision stage of the lexical decision rather than from enhanced identification of the target itself. A priming effect could arise from decision processes in the lexical decision task in the following way. Although a masked morphological prime may not be consciously identified, it may be processed to a semantic level during the course of target word identification. Detection of the morphological or seman- tic relation between the prime and target, perhaps through a semantic matching process (Neely, 1991), may then serve as evidence in favor of the decision that the target is a word. A similar suggestion concerning the postlexical influence of masked semantic primes in the lexical decision task has been put forward by Carr and Dagenbach (1990) and by Sereno (1991). Moreover, Sereno obtained masked priming effects with semantic and with syntactic primes in a lexical decision task, but not in a word naming task, in which case it is assumed that decision processes make a minimal contribution.

Against the possibility that masked priming effects do not involve lexical knowledge at all, Frost, Forster, and Deutsch (1997) obtained reliable morphological priming using Hebrew materials relative to appropriate orthographic control items in both lexical decision and naming tasks. Moreover, Gollan, Forster, and Frost (1997) found significant cross-language masked priming in which prime and target pairs were Hebrew-English translation equivalents (subjects were bilingual, with Hebrew as their first language). This priming effect was obtain with both cognates and noncognates in a lexical decision task. These results indicate that, at least in Hebrew, masked primes can provide preliminary access to lexical knowledge that is relevant to a target word.

As a further test of the basis of masked morphological priming in English, we included in Experiment 2 a morphological prime condition and an orthographic prime condition. Orthographic primes were matched to morphological primes with respect to orthographic similarity to target words. Nonwords were used as orthographic primes so that this matching could be as close as possible. If morphological primes speed word identification through access to a morphological representation, then these primes should be more effective than matched orthographic primes. This experiment provided an opportunity to test this hypothesis using the naming task, which should be relatively free of postlexical influences that may affect the lexical decision task. For nonword targets, only repetition and orthographic primes were used because morphological structure does not exist for nonwords.

\section{Method}

Subjects. A different sample of 36 subjects was recruited from the same source as in Experiment 1.

Materials. A set of 80 critical words was selected with the constraint that each word had a morphologically related word of the same length and the same initial phoneme, which served as the morphological prime. An orthographic prime was constructed for each target so that it was matched to the morphological prime with respect to orthographic similarity to the target. Each orthographic prime was created by changing one letter of the morphological prime (never the first letter) to a different letter with the same shape (i.e., ascender or descender), yielding a pronounceable nonword. The letter to be changed was selected so that it did not match the letter occupying that position in the target word, and the substituted letter also met this constraint. An unrelated prime consisting of a pronounceable nonword was also selected for each target with the 
constraint that it be of the same length as the target word and have no letters in common with the target at any ordinal position in the word except for the first letter. All primes shared the same first letter as their corresponding target to prevent the onset interference effect observed by Forster and Davis (1991). For example, the three primes for the target word lend were lent, lenk, and lort. The targets ranged in frequency from 0 to 1,207 per million in the Kučera and Francis (1967) norms, with a mean of 119 per million, and they ranged in length from three to six characters.

A set of 60 pronounceable nonword targets was constructed. These targets ranged in length from three to six characters. An orthographic prime was constructed for each nonword target by changing one letter (other than the first letter) of the target item to a different letter of the same shape. The position of the changed letter varied across letter positions in the same proportion as the orthographic primes for word targets. An unrelated word prime was selected in the same manner as for word targets. For example, the two primes for the nonword target parn were pern and pice.

Through an oversight, for a few targets the initial phoneme of the target differed from that of its unrelated prime, although those items shared the same initial letter (e.g., kract-KNEEL, crim-CHOT). Data from trials involving such targets were not included in the analyses reported here. Therefore, the reported data are based on 69 critical words and 52 critical nonwords. These critical items and their respective primes are shown in Appendix B.

A set of six practice items was constructed that consisted of three word and three nonword targets. One target of each type was paired with a repetition, an orthographic, and an unrelated prime.

Design. Each subject was presented 80 word targets and 60 nonword targets. Twenty word targets were assigned to each of four priming conditions: repetition, morphological, orthographic, and unrelated. Twenty nonword targets were assigned to each of three priming conditions: repetition, orthographic, and unrelated. The assignments of targets to priming conditions were counterbalanced across subjects so that each item appeared equally often in each priming condition.

Procedure. Instructions and stimulus materials were presented on a Macintosh II microcomputer equipped with a monochrome monitor. Stimulus presentation was synchronized with the monitor's raster scan cycle, permitting stimulus durations to be controlled to the nearest $15 \mathrm{msec}$. Naming responses were detected by a microphone connected to a voice-activated relay. The relay was wired into the Macintosh mouse so that when it was triggered it simulated a mouse click, permitting measurement of response latency. The experimenter viewed a second monitor that displayed the target item on each trial and pressed the appropriate key after each vocal response to indicate whether the response was correct.

Each stimulus presented during a trial was centered in a field that was eight character spaces wide and bounded by a single hyphen at either end. The field was located at the center of the computer monitor, and the hyphens remained in view as the contents in the field were changed. A trial began with a row of Xs presented for $495 \mathrm{msec}$. The length of this string was the same as the length of the upcoming target word. The Xs were then replaced by a $60-\mathrm{msec}$ presentation of the prime stimulus in lowercase letters. Finally, the target item appeared in uppercase letters and remained in view until the subject made a vocal response. The experimenter then made a keypress to classify the response as correct or invalid (a mispronunciation or accidental triggering of the voice-activated relay). The next trial began 500 msec after the experimenter's keypress.

The six practice trials were presented first, and then the subjects were given an opportunity to ask questions about the procedure. The 140 critical trials were then presented in random order. After each set of 35 critical trials, the subjects were given an opportunity to take a short rest
Table 2

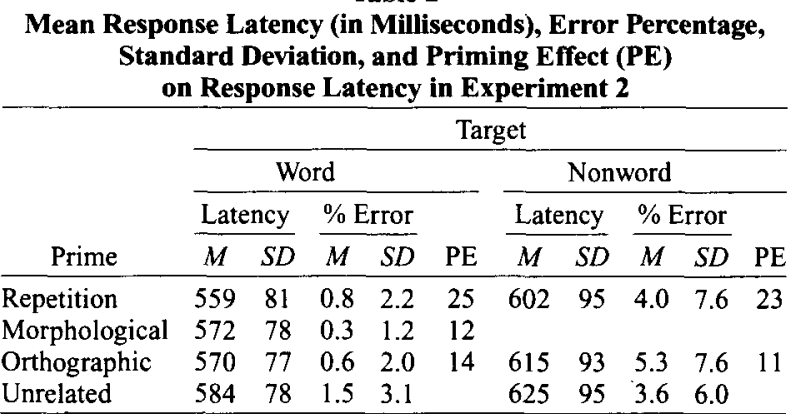

\section{Results and Discussion}

As in Experiment 1, trials on which response latency was lower than $200 \mathrm{msec}$ or greater than $1,800 \mathrm{msec}$ were excluded from the analyses. By this criterion, 10 of the 4,356 trials $(0.2 \%)$ were eliminated. For each subject, median response latency for each priming condition was computed on the basis of trials on which a correct naming response was made. The mean of the subjects' median latencies and the mean error percentage (with errors defined as in Experiment 1) are shown in Table 2. Separate sets of ANOVAs were computed to test for repetition priming, to compare morphological and orthographic priming conditions, and to test for orthographic priming. As in Experiment 1, separate ANOVAs were computed with subjects as the random variable and with items as the random variable. The Type I error rate in all analyses was .05 .

Repetition priming. The repetition priming effects shown in Table 2 indicate that both word and nonword targets produced similar effects. Separate ANOVAs for word and for nonword targets verified that these effects were reliable $\left[F_{1}(1,35)=16.25, M S_{\mathrm{e}}=697, F_{2}(1,68)=\right.$ $12.52, M S_{\mathrm{e}}=1,736$, for words, and $F_{1}(1,35)=17.64$, $M S_{\mathrm{e}}=544, F_{2}(1,51)=7.97, M S_{\mathrm{e}}=1,013$, for nonwords]. Corresponding analyses of error percentage revealed no reliable priming effect (all $F_{\mathrm{s}}<1.7$ ).

The priming effect on naming latency among word and nonword targets was compared by computing a word and a nonword priming score for each subject and a priming score for each item. The mean priming scores for words and nonwords were not reliably different in either the subjects or the items analysis $(F \mathbf{S}<1)$. The upper bound on power to detect a difference in priming between these two sets of items was computed by assuming a difference equal to the full size of the priming effect for word targets (i.e., a situation in which full priming is found for words, but no priming is found for nonwords). This method produced power estimates of .87 and .72 for the subjects and items analyses, respectively.

The repetition priming effects found in Experiment 2 replicate the results observed in Experiment 1 with respect to the comparison between word and nonword targets. Both types of targets benefit from masked repetition 
priming and to a similar extent. This finding supports the proposal that there is a substantial nonlexical contribution to masked priming effects in the naming task.

Morphological versus orthographic primes. The possibility that morphological structure in the lexicon contributes to the identification of target words in masked priming was tested by comparing performance in the morphological and orthographic priming conditions. These two types of prime were matched with respect to their orthographic similarity to target words, but morphological primes had the additional potential advantage of a morphological link to their target words. A comparison of these two types of primes with response latency as the dependent variable yielded no hint of an effect of prime type $(F \mathrm{~S}<1)$. A similar analysis of error percentage also failed to show any evidence of a difference between these two types of prime $\left(F_{\mathrm{S}}<1\right)$.

An estimate of the upper bound on the power to detect a response latency difference between these two priming conditions was computed using the difference between the morphological and the unrelated prime conditions (i.e., $12 \mathrm{msec}$ ) as the effect size. This approach yielded power estimates of .52 and .44 in the subject and item analyses, respectively.

Although the failure to find a difference between the morphological and orthographic priming conditions suggests that morphological structure played no significant role in generating masked priming effects, the low power associated with this comparison argues against drawing strong conclusions from this result. Nevertheless, the present result is consistent with the possibility that the benefit associated with masked morphological priming in this experiment is attributable entirely to orthographic overlap between the prime and target.

Orthographic priming. Masked orthographic priming among word and nonword targets was assessed in separate sets of ANOVAs with prime (orthographic vs. unrelated) as the factor and response latency as the dependent variable. These ANOVAs revealed a significant orthographic priming effect for words, although the effect only approached significance in the items analysis $\left[F_{1}(1,35)=5.54, M S_{\mathrm{e}}=622, F_{2}(1,68)=2.93, M S_{\mathrm{e}}=\right.$ $1,390, p<.10]$.

For nonword targets, the orthographic priming effect approached significance in the subjects analysis $\left[F_{1}(1,35)=\right.$ $\left.3.01, M S_{\mathrm{e}}=674, F_{2}(1,51)=1.13, M S_{\mathrm{e}}=1,198\right]$. The corresponding analyses of error percentages revealed a reliable effect of orthographic priming for word targets $\left[F_{1}(1,35)=4.09, M S_{\mathrm{e}}=4.16, p=.05, F_{2}(1,68)=4.69\right.$, $\left.M S_{\mathrm{e}}=9.32\right]$. For nonword targets, a reverse priming effect approached significance in the subjects analysis, with more errors committed when an orthographic prime was used $\left[F_{1}(1,35)=3.33, M S_{\mathrm{e}}=15.00, p<.10, F_{2}(1,51)=\right.$ $\left.1.92, M S_{\mathrm{e}}=49.88\right]$, suggesting a possible speed-accuracy tradeoff. In Experiment 2, then, the effects of orthographic primes were less stable for nonwords than for words, as was the case in Experiment 1.

\section{GENERAL DISCUSSION}

Three main results emerged from the experiments reported here. First, masked repetition priming of similar magnitude was obtained for both word and nonword targets in the naming task. These priming effects were found even though care was taken to avoid the Stroop-like interference found by Forster and Davis (1991) when unrelated primes and targets differed in the their first phoneme. In the present experiments, unrelated primes and targets shared the same first phoneme, so the repetition priming effects could not have been due to different onsets in unrelated primes and targets. The robust priming effect for nonword targets dispels any notion that the effect is spurious or weak. Taken together with the masked priming of nonwords in the lexical decision task reported by Bodner and Masson (1997), the present results provide strong support for the conclusion that masked repetition priming of nonword targets can be as large as that found with word targets.

Second, in contrast to repetition priming, masked orthographic priming was more stable for word than for nonword targets. It would be unwise to draw strong conclusions from this result, however, because it is known that masked orthographic priming of word targets in the word naming task is constrained by the size of the orthographic neighborhood of the prime and target (Forster \& Davis, 1991): Items with fewer orthographic neighbors yield priming, whereas items with many neighbors do not. Because we did not manipulate orthographic neighborhood in the present experiments, it could be that the pattern of orthographic priming of words and nonwords came about because of a differential mixture of large and small neighborhood sizes among the primes and targets in the two sets of items. This possible confound, combined with the finding of reliable orthographic priming for nonwords in the subjects analysis of Experiment 1 , suggests a very interesting possibility that deserves to be tested. Namely, masked orthographic priming of nonword targets may be subject to the same neighborhood size constraint that applies to word targets. If that were the case, accounts of neighborhood size effects in this paradigm would take on a somewhat different flavor. Rather than interpreting those effects as reflecting constraints imposed by a lexicon of known words (Forster \& Davis, 1991; Forster et al., 1987; Forster \& Taft, 1994), a more plausible account might involve connectionist models that emphasize mappings between sublexical units representing orthography and phonology (e.g., Plaut, McClelland, Seidenberg, \& Patterson, 1996; Seidenberg \& McClelland, 1989; Van Orden, Pennington, \& Stone, 1990).

Third, masked morphological primes had no effect beyond that attributable to their orthographic similarity to the targets. The failure to find a morphological component of masked priming suggests that morphological primes do not reliably contact lexical information relevant to their targets. This conclusion must be tentative, 
however, because reliable morphological priming effects with appropriate orthographic control items have been observed in French with the lexical decision task (Grainger et al., 1991) and in Hebrew with the lexical decision task and the naming task (Frost et al., 1997). If reliable masked morphological priming were found in English, it would support the view that masked primes contact some form of semantic information about word targets. This effect, however, would not necessarily indicate the existence of a separate morphological representation. Rueckl, Mikolinski, Raveh, Miner, and Mars (1997) showed that morphological priming in a long-term priming paradigm varied as a direct function of orthographic similarity. That relation was used by Rueckl et al. to support a connectionist account of morphological priming in which morphological relations provide a source of structure in mapping orthography to semantics. Thus, morphological priming effects could indicate a role for either a morphological representation or more general semantic knowledge.

The results reported here clearly indicate that there is a nonlexical contribution to masked repetition priming in the naming task. We propose that presentation of a masked prime initiates orthographic or phonological processing that is similar to the processing applied to the subsequently presented target item. This similarity forms a basis for the priming effect, regardless of the lexical status of the target. Other results, such as those involving masked morphological priming in languages other than English (Frost et al., 1997; Grainger et al., 1991) and cross-language masked priming involving different scripts (Gollan et al., 1997), indicate that there is a lexical or semantic contribution to masked priming as well. It is not clear whether lack of statistical power or nonadditivity among multiple sources of priming has made it difficult to detect reliable differences between masked repetition priming of word and nonword targets. In any case, however, the contribution of nonlexical factors in masked priming indicates that caution must be exercised in interpreting results from this paradigm.

We see two possible ways in which processing of a masked prime might influence the processing of the target item. First, processing of the prime may be ongoing when the target is presented. Because of the similarity between the processes applied to the prime and those initiated by presentation of the target, the two may be integrated, providing for more efficient encoding of the target. Alternatively, processing operations applied to the prime may be terminated by masking created by presentation of the target, but an episodic representation of that processing may nevertheless be formed (see also Bodner \& Masson, 1997; Whittlesea \& Jacoby, 1990). On this account, even without awareness of the prime event, an episodic representation is created, perhaps through a learning mechanism such as that used in connectionist models described by S. Becker, Moscovitch, Behrmann, and Joordens (1997) and by Rueckl et al. (1997). In those models, the effect of the priming episode can be charac- terized as the deepening of an item's basin of attraction (or the creation of a basin in the case of a nonword). Processing of the target may then benefit from an episodic representation of the prime event in the same way that memory for instances of prior processing forms the basis for skilled task performance (e.g., Logan, 1988; Masson, 1986).

Neither of these possibilities makes an appeal to opening of lexical entries as the basis for masked priming effects. The involvement of nonlexical encoding operations in masked priming does not imply, however, that word identification processes cannot be meaningfully studied with the masked priming paradigm. On the contrary, the present results indicate that the paradigm is capable of producing important evidence concerning the nature of the processes that are invoked in the earliest stages of encoding letter strings. An important direction for future research with this paradigm is to examine divergence in the processing streams associated with words and nonwords.

\section{REFERENCES}

BECKER, C. A. (1979). Semantic contexts and word frequency effects in visual word recognition. Journal of Experimental Psychology: Human Perception \& Performance, 5, 252-259.

Becker, S., Moscovitch, M., Behrmann, M., \& Joordens, S. (1997). Long-term semantic priming: A computational account and empirical evidence. Journal of Experimental Psychology: Learning, Memory, \& Cognition, 23, 1059-1082.

BESNER, D., \& SMITH, M. C. (1992). Models of visual word recognition: When obscuring the stimulus yields a clearer view. Journal of Experimental Psychology: Learning, Memory, \& Cognition, 18, 468-482.

BESNER, D., \& SwAN, M. (1982). Models of lexical access in visual word recognition. Quarterly Journal of Experimental Psychology, 34A, 313-325.

BoDnER, G. E., \& Masson, M. E. J. (1997). Masked repetition priming of words and nonwords: Evidence for a nonlexical basis for priming. Journal of Memory \& Language, 37, 268-293.

BOROWSKY, R., \& BESNER, D. (1993). Visual word recognition: A multistage activation model. Journal of Experimental Psychology: Learning, Memory, \& Cognition, 19, 813-840.

CARR, T. H., \& DagenbaCh, D. (1990). Semantic priming and repetition priming from masked words: Evidence for a center-surround attentional mechanism in perceptual recognition. Journal of Experimental Psychology: Learning, Memory, \& Cognition, 16, 341-350.

DUCHEK, J. M., \& NeELY, J. H. (1989). A dissociative word-frequency $\times$ levels-of-processing interaction in episodic recognition and lexical decision tasks. Memory \& Cognition, 17, 148-162.

EvetT, L. J., \& HumPHREYS, G. W. (1981). The use of abstract graphemic information in lexical access. Quarterly Journal of Experimental Psychology, 33A, 325-350.

Ferrand, L., Grainger, J., \& Segui, J. (1994). A study of masked form priming in picture and word naming. Memory \& Cognition, 22, 431-441.

Feustel, T. C., Shiffrin, R. M., \& Salasoo, A. (1983). Episodic and lexical contributions to the repetition effect in word identification. Journal of Experimental Psychology: General, 112, 309-346.

Forster, K. I. (1976). Accessing the mental lexicon. In R. J. Wales \& E. Walker (Eds.), New approaches to language mechanisms (pp. 257287). Amsterdam: North-Holland.

FORSTER, K. I. (1985). Lexical acquisition and the modular lexicon. Language \& Cognitive Processes, 1, 87-108.

FORSTER, K. I. (1987). Form priming with masked primes: The best match hypothesis. In M. Coltheart (Ed.), Attention and performance XII: The psychology of reading (pp. 127-146). Hillsdale, NJ: Erlbaum. 
Forster, K. I., \& DAVIS, C. (1984). Repetition priming and frequency attenuation in lexical access. Journal of Experimental Psychology: Learning, Memory, \& Cognition, 10, 680-698.

Forster, K. I., \& DAVIS, C. (1991). The density constraint on formpriming in the naming task: Interference effects from a masked prime. Journal of Memory \& Language, 30, 1-25.

FoRSTER, K. I., DAVIS, C., SCHOKNECHT, C., \& CARTER, R. (1987). Masked priming with graphemically related forms: Repetition or partial activation? Quarterly Journal of Experimental Psychology, 39A, 211-251.

FORSTER, K. I., \& TAFT, M. (1994). Bodies, antibodies, and neighborhooddensity effects in masked form priming. Journal of Experimental Psy. chology: Learning, Memory, \& Cognition, 20, 844-863.

Frost, R., Forster, K. I., \& DeutsCh, A. (1997). What can we learn from the morphology of Hebrew? A masked-priming investigation of morphological representation. Journal of Experimental Psychology: Learning, Memory, \& Cognition, 23, 829-856.

Gollan, T. H., FoRSTER, K. I., \& Frost, R. (1997). Translation priming with different scripts: Masked priming with cognates and noncognates in Hebrew-English bilinguals. Journal of Experimental Psychology: Learning, Memory, \& Cognition, 23, $1122-1139$.

Grainger, J., Colé, P., \& Segui, J. (1991). Masked morphological priming in visual word recognition. Journal of Memory \& Language, 30, 370-384.

Grainger, J., \& Ferrand, L. (1991, November). Phonology and orthography in visual word recognition. Paper presented at the annual meeting of the Psychonomic Society, San Francisco.

HumphreYs, G. W., BESNER, D., \& QUiNLAN, P. T. (1988). Event perception and the word repetition effect. Journal of Experimental Psychology: General, 117, 51-67.

Humphreys, G. W., EvetT, L. J., \& Quinlan, P. T. (1990). Orthographic processing in visual word identification. Cognitive Psychology, 22, 517-560.

HumPhreys, G. W., EvetT, L. J., Quinlan, P. T., \& Besner, D. (1987). Orthographic priming: Qualitative differences between priming from identified and unidentified primes. In M. Coltheart (Ed.), Attention and performance XII: The psychology of reading (pp. 105-125). Hillsdale, NJ: Erlbaum.

JACOBY, L. L., \& DALlAS, M. (1981). On the relationship between autobiographical memory and perceptual learning. Journal of Experimental Psychology: General, 110, 306-340.

KIRSNER, K., \& SMITH, M. C. (1974). Modality effects in word identification. Memory \& Cognition, 2, 637-640.

KirSner, K., \& SpeElman, C. (1996). Skill acquisition and repetition priming: One principle, many processes? Journal of Experimental Psychology: Learning, Memory, \& Cognition, 22, 563-575.

KuČERA, J., \& FRANCIS, W. N. (1967). Computational analysis of present day American English. Providence, RI: Brown University Press.

LoGAN, G. D. (1988). Toward an instance theory of automatization. Psychological Review, 95, 492-527.

Lukatela, G., \& Turvey, M. T. (1994a). Visual lexical access is initially phonological: 1 . Evidence from associative priming by words, homophones, and pseudohomophones. Journal of Experimental Psychology: General, 123, 107-128.

Lukatela, G., \& TuRveY, M. T. (1994b). Visual lexical access is initially phonological: 2 . Evidence from phonological priming by homo- phones and pseudohomophones. Journal of Experimental Psychology: General, 123, 331-353.

MAsSON, M. E. J. (1986). Identification of typographically transformed words: Instance-based skill acquisition. Journal of Experimental Psychology: Learning, Memory, \& Cognition, 12, 479-488.

MCKONE, E. (1995). Short-term implicit memory for words and nonwords. Journal of Experimental Psychology: Learning, Memory, \& Cognition, 21, 1008-1126.

MCRAE, K., JARED, D., \& SeIdenberg, M. S. (1990). On the roles of frequency and lexical access in word naming. Journal of Memory \& Language, 29, 43-65.

NEELY, J. H. (1991). Semantic priming effects in visual word recognition: A selective review of current findings and theories. In D. Besner \& G. W. Humphreys (Eds.), Basic processes in reading: Visual word recognition (pp. 264-336). Hillsdale, NJ: Erlbaum.

NoRrIS, D. (1984). The effects of frequency, repetition, and stimulus quality in visual word recognition. Quarterly Journal of Experimental Psychology, 36A, 507-518.

Perfetti, C. A., \& Bell, L. (1991). Phonemic activation during the first $40 \mathrm{~ms}$ of word identification: Evidence from backward masking and priming. Journal of Memory \& Language, 30, 473-485.

Plaut, D. C., McClelland, J. L., SeidenberG, M. S., \& Patterson, K. (1996). Understanding normal and impaired word reading: Computational principles in quasi-regular domains. Psychological Review, 103, 56-115.

Rajaram, S., \& NeEly, J. H. (1992). Dissociative masked repetition priming and word frequency effects in lexical decision and episodic recognition tasks. Journal of Memory \& Language, 31, 152-182.

Rueckl, J. G., Mikolinski, M., Raveh, M., Miner, C. S., \& Mars, F. (1997). Morphological priming, fragment completion, and connectionist networks. Journal of Memory \& Language, 36, 382-405.

Scarborough, D. L., Cortese, D., \& Scarborough, H. S. (1977). Frequency and repetition effects in lexical memory. Journal of Experimental Psychology: Human Perception \& Performance, 3, 1-17.

SEGUI, J., \& GRaINGER, J. (1990). Priming word recognition with orthographic neighbors: Effects of relative prime-target frequency. Journal of Experimental Psychology: Human Perception \& Performance, $16,65-76$.

SeidenberG, M. S., \& MCClelland, J. L. (1989). A distributed, developmental model of word recognition and naming. Psychological Review, 96, 523-568.

SERENO, J. A. (1991). Graphemic, associative, and syntactic priming effects at a brief stimulus onset asynchrony in lexical decision and naming. Journal of Experimental Psychology: Learning, Memory, \& Cognition, 17, 459-477.

StanNers, R. F., \& Forbach, G. B. (1973). Analysis of letter strings in word recognition. Journal of Experimental Psychology, 98, 31-35.

ULRICH, R., \& MILLER, J. (1994). Effects of truncation on reaction time analysis. Journal of Experimental Psychology: General, 123, 34-80.

Van Orden, G. C., Pennington, B. F., \& Stone, G. O. (1990). Word identification in reading and the promise of a subsymbolic psycholinguistics. Psychological Review, 97, 488-522.

WhITTLESEA, B. W. A., \& JACOBY, L. L. (1990). Interaction of prime repetition with visual degradation: Is priming a retrieval phenomenon? Journal of Memory \& Language, 29, 546-565. 
APPENDIX A

Critical Items Used in Experiment 1

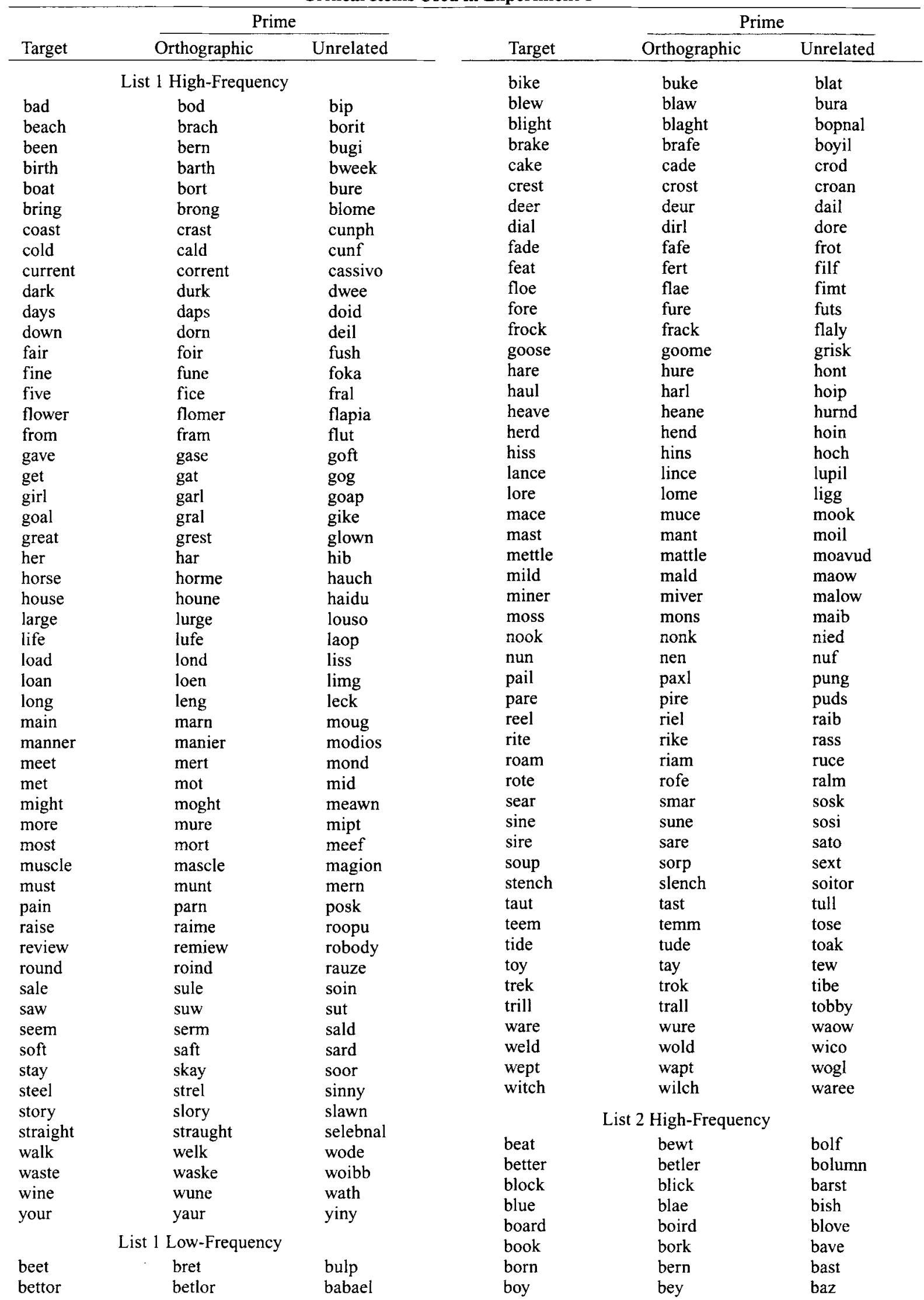


APPENDIX A (Continued)

\begin{tabular}{|c|c|c|c|c|c|}
\hline \multirow[b]{2}{*}{ Target } & \multicolumn{2}{|c|}{ Prime } & \multirow[b]{2}{*}{ Target } & \multicolumn{2}{|c|}{ Prime } \\
\hline & Orthographic & Unrelated & & Orthographic & Unrelated \\
\hline break & bresk & bouks & fife & fofe & fach \\
\hline course & courme & catant & flea & flia & figt \\
\hline cross & crons & cluit & flour & floer & fevip \\
\hline dear & deor & dilm & fold & fald & feem \\
\hline feet & fert & foop & fray & froy & fown \\
\hline fire & fise & fanf & fret & frit & feal \\
\hline floor & floir & fitet & ghost & ghast & ghade \\
\hline flow & fliw & feck & goat & gort & gide \\
\hline four & foir & feef & grate & grite & gliff \\
\hline french & frunch & fisist & grief & gruef & gooth \\
\hline group & groip & glist & hive & hove & hapo \\
\hline hair & heir & hoom & hoarse & hoarme & honogy \\
\hline hall & holl & hesp & hound & hoand & hewer \\
\hline heard & herrd & holvs & keen & kuen & kint \\
\hline heat & hent & houn & lad & lud & lup \\
\hline held & hald & hist & lark & lork & woop \\
\hline home & hime & hing & lode & lote & lato \\
\hline kept & kopt & kimt & lone & loie & lupt \\
\hline last & lant & lilm & lost & loat & lill \\
\hline leave & lerve & loing & louse & loune & lotap \\
\hline like & loke & lont & lurch & lursh & leaft \\
\hline loose & lonse & luard & mane & mune & moir \\
\hline metal & mutal & moorp & manor & menor & mefel \\
\hline minor & munor & melan & mete & mefe & mady \\
\hline miss & mirs & muke & mite & mife & mapa \\
\hline night & naght & neter & mole & mele & mivo \\
\hline none & nane & namg & mussel & mursel & moitor \\
\hline paid & paed & piws & noun & noan & nise \\
\hline pair & paur & plit & pane & pame & purk \\
\hline pale & pake & ponk & paw & puw & pog \\
\hline real & rerl & rogy & pet & pst & pir \\
\hline rear & reor & rowe & rave & rame & riop \\
\hline right & reght & rofer & raze & rane & rops \\
\hline sign & sagn & soll & revue & ravue & ragmu \\
\hline six & $\operatorname{sux}$ & sot & sail & sarl & sush \\
\hline still & stell & sobee & seam & sram & silm \\
\hline take & tike & tigs & sore & sone & sask \\
\hline taught & taight & tollor & steal & sleal & soffi \\
\hline team & toam & toug & stir & skir & suby \\
\hline tied & tird & $\tan p$ & storey & skorey & sobadu \\
\hline trip & trep & tull & waist & warst & weech \\
\hline well & wull & wuny & whine & whone & wooth \\
\hline west & wast & wulm & whirl & whorl & wighe \\
\hline where & wheme & wouss & yore & yone & yakko \\
\hline which & whech & wokus & \multicolumn{3}{|c|}{ Nonword Targets and Primes } \\
\hline \multirow{2}{*}{\multicolumn{3}{|c|}{ List 2 Low-Frequency }} & barl & berl & bonk \\
\hline & & & blins & blans & bramk \\
\hline barge & berge & bloll & bonf & benf & brup \\
\hline beech & beesh & blain & borth & burth & bemed \\
\hline berth & barth & boick & bouns & bours & beabs \\
\hline boast & borst & beere & brean & broan & bluss \\
\hline bong & beng & bafe & brinf & branf & bleam \\
\hline bust & bist & birk & closk & clask & crumk \\
\hline currant & cerrant & cogicol & coab & corb & cand \\
\hline daze & dize & dolk & dask & dosk & dult \\
\hline dine & dise & dort & dast & dest & dopi \\
\hline entrants & enkrants & elvoromd & dipth & dapth & drame \\
\hline fare & fure & foom & dreb & drub & dolp \\
\hline
\end{tabular}


APPENDIX A (Continued)

\begin{tabular}{|c|c|c|c|c|c|c|}
\hline \multirow[b]{2}{*}{ Target } & \multicolumn{2}{|c|}{ Prime } & \multirow[b]{2}{*}{ Target } & \multicolumn{3}{|c|}{ Prime } \\
\hline & Orthographic & Unrelated & & Morph. & Orthog. & Unrelated \\
\hline drens & drans & ditit & loods & & loids & lanti \\
\hline fant & fint & foke & lurve & & lirve & lovst \\
\hline fath & feth & fomp & moop & & momp & maku \\
\hline firt & furt & fope & nort & & nurt & nase \\
\hline fofty & fofly & fiald & nump & & nurp & nalk \\
\hline fosh & fesh & flin & pird & & pard & polk \\
\hline fost & fust & fipt & plars & & plams & peebb \\
\hline frain & froin & fated & pule & & pufe & pont \\
\hline funt & fent & fods & rence & & rance & ratid \\
\hline gald & guld & geef & resk & & renk & raby \\
\hline gare & gere & gops & ribe & & rabe & ronk \\
\hline gaste & gaske & glomi & rint & & ront & ropy \\
\hline geest & geent & glorp & routh & & ronth & rasly \\
\hline glay & gley & gost & sant & & $\operatorname{sint}$ & serg \\
\hline greb & grib & gask & selk & & salk & suty \\
\hline grice & gruce & gulst & snife & & snafe & slasp \\
\hline guarm & guurm & goobe & tase & & tave & tirk \\
\hline hilp & holp & hars & tash & & tish & torf \\
\hline hode & hade & hupp & tind & & tand & temk \\
\hline keps & kips & klod & tufe & & tafe & tirt \\
\hline lafe & lefe & loog & yain & & yaun & yome \\
\hline laint & laist & loove & & & & \\
\hline
\end{tabular}

APPENDIX B

Critical Items Used in Experiment 2

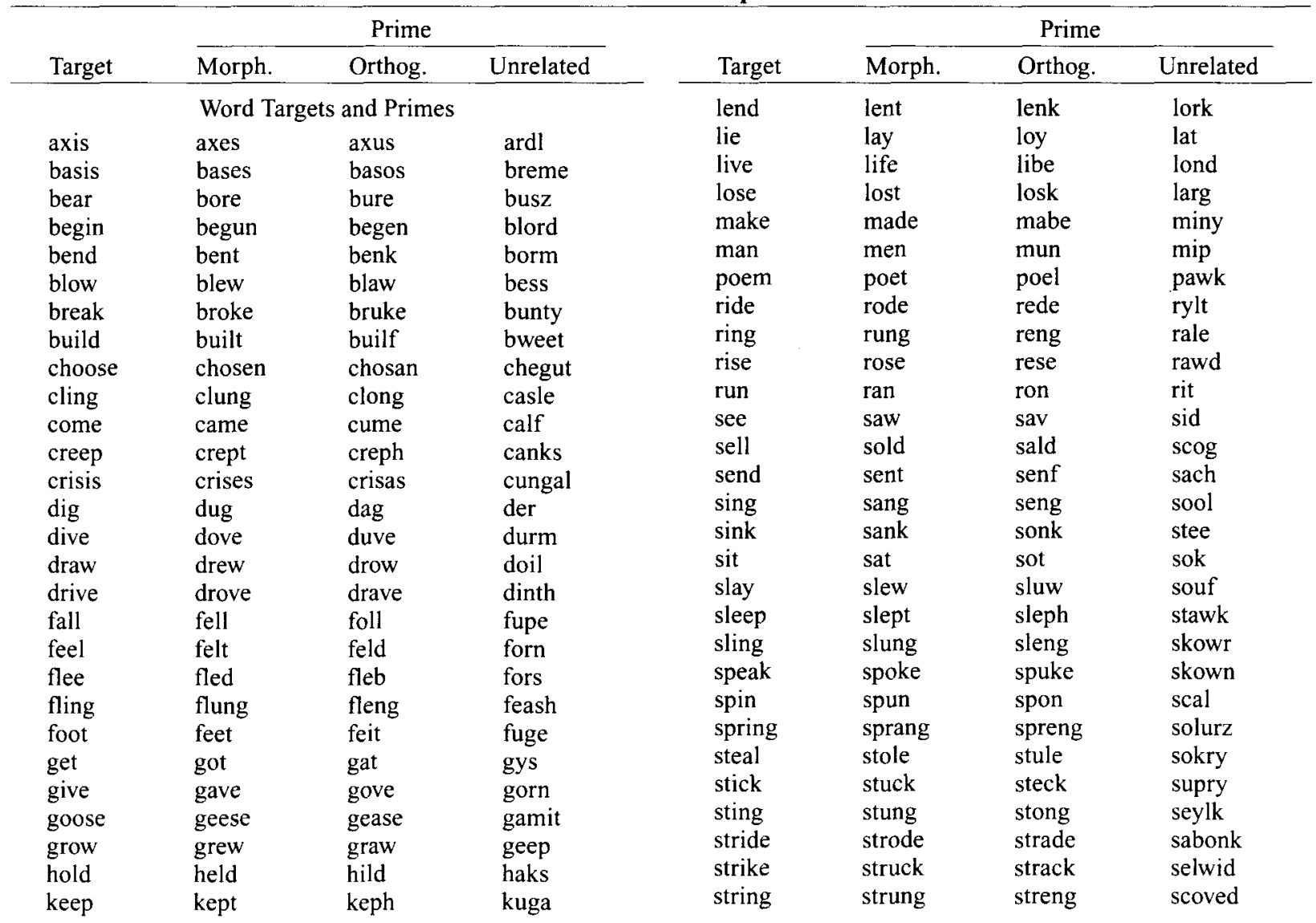


APPENDIX B (Continued)

\begin{tabular}{|c|c|c|c|c|c|c|}
\hline \multirow[b]{2}{*}{ Target } & \multicolumn{3}{|c|}{ Prime } & \multirow[b]{2}{*}{ Target } & \multicolumn{2}{|c|}{ Prime } \\
\hline & Morph. & Orthog. & Unrelated & & Orthog. & Unrelated \\
\hline swear & swore & swire & supul & heane & heame & hosut \\
\hline sweep & swept & sweph & sorch & kamer & kumer & kocit \\
\hline swim & swam & swom & sout & kart & kast & koun \\
\hline swing & swung & swong & surch & lar & lur & leb \\
\hline take & took & touk & tust & lince & licce & lurad \\
\hline tear & tore & ture & tigh & lome & lume & ladd \\
\hline tell & told & tild & tilk & loun & leun & lert \\
\hline tooth & teeth & teoth & treek & lud & lod & ley \\
\hline wear & wore & wure & whut & marn & mern & mufe \\
\hline weep & wept & weph & wuds & mof & maf & $\mathrm{mab}$ \\
\hline win & won & wen & wah & mons & mors & miak \\
\hline \multirow[t]{2}{*}{ woman } & women & womon & whurch & munt & mant & morf \\
\hline & \multicolumn{3}{|c|}{ Prime } & mure & muce & maft \\
\hline Target & & og. & Unrelated & $\begin{array}{l}\text { nen } \\
\text { parn }\end{array}$ & $\begin{array}{l}\operatorname{nin} \\
\text { pern }\end{array}$ & $\begin{array}{l}\text { nov } \\
\text { pice }\end{array}$ \\
\hline \multicolumn{4}{|c|}{ Nonword Targets and Primes } & puv & pav & pir \\
\hline & & & bayk & raime & raize & rokol \\
\hline bort & & & bave & reil & ruil & rahd \\
\hline brafe & & & bohit & rofe & rafe & rint \\
\hline brean & & & blosk & routh & rauth & rizep \\
\hline buke & & & bant & $\begin{array}{l}\text { sard } \\
\text { smech }\end{array}$ & surd & $\begin{array}{l}\text { suty } \\
\text { sungr }\end{array}$ \\
\hline crast & & & clowy & $\begin{array}{l}\text { smech } \\
\text { snude }\end{array}$ & snube & $\begin{array}{l}\text { sunor } \\
\text { sorim }\end{array}$ \\
\hline dest & & & dibe & $\begin{array}{l}\text { Snude } \\
\text { strel }\end{array}$ & $\begin{array}{l}\text { Snuoe } \\
\text { stral }\end{array}$ & soind \\
\hline dirl & & & dend & $\begin{array}{l}\text { strel } \\
\text { sule }\end{array}$ & $\begin{array}{l}\text { stral } \\
\text { sile }\end{array}$ & skor \\
\hline doane & & & dulfs & sune & suve & sarl \\
\hline drell & & & dasmo & surp & sarp & sade \\
\hline fert & & & flod & tast & tant & tibe \\
\hline flomer & & & fastin & trang & trung & tewle \\
\hline foir & & & fesk & treen & trean & toosh \\
\hline frack & & & fuste & tude & tule & trit \\
\hline fune & & & farz & varge & vange & volit \\
\hline fure & & & fimp & waske & weske & woght \\
\hline $\begin{array}{l}\text { gral } \\
\text { grest }\end{array}$ & & & $\begin{array}{l}\text { gosk } \\
\text { goluz }\end{array}$ & wune & wuze & waps \\
\hline
\end{tabular}

Note-Morph., morphological; Orthog., orthographic

(Manuscript received June 11, 1997;

revision accepted for publication June $15,1998$. 